\title{
Implementasi Naive Bayes Classifier pada Opinion Mining Berdasarkan Tweets Masyarakat Terkait Kinerja Presiden dalam Aspek Ekonomi
}

\author{
Sri Juniarsih ${ }^{\mathrm{a} 1}$, Eva Faja Ripanti ${ }^{\mathrm{a} 2}$, Enda Esyudha Pratama ${ }^{\mathrm{a} 3}$ \\ ${ }^{a}$ Program Studi Sarjana Informatika, Universitas Tanjungpura \\ Jl. Prof. Dr. H. Hadari Nawawi, Kota Pontianak, 78115 \\ ${ }^{1}$ juniasihhegmail.com \\ evaripanti@untan.ac.id \\ ${ }^{3}$ endalinformatika.untan.ac.id
}

\begin{abstract}
Abstrak
Media sosial salah satunya Twitter dimanfaatkan sebagai sarana untuk lebih dekat dengan masyarakat. Hal tersebut dapat memberikan wawasan yang mendalam tentang apa yang masyarakat inginkan. Tujuan dari penelitian ini adalah menghasilkan mesin yang mampu mengklasifikasikan tweets masyarakat terkait kinerja presiden dalam aspek ekonomi ke dalam kelas positif dan negatif. Aspek utama (ekonomi) diturunkan menjadi parameter "ekonomi Indonesia", "lapangan pekerjaan" dan "rupiah". Text preprocessing yang digunakan yaitu cleaning, case folding, normalisasi, filtering, dan stemming. Penelitian ini menerapkan teknik scraping sebagai teknik pengumpulan data tweets, TF-IDF sebagai metode pembobotan kata, Naive Bayes Classifier sebagai algoritma pengklasifikasian, serta Confusion Matrix sebagai metode pengujian. Training data terdiri dari training data A yang berjumlah 600 dokumen dari data tweets, dan training data B yang berjumlah 158 dokumen yang disusun berdasarkan pola "parameter + kata independen". Klasifikasi yang dilakukan oleh opinion mining machine secara keseluruhan (gabungan semua parameter) dapat dinyatakan sebagai "Good Classification". Berdasarkan pengujian Skenario 1 (klasifikasi menggunakan training data A), mesin mampu mengklasifikasikan 540 testing data (gabungan semua parameter) dengan akurasi sebesar $87.96 \%$ dan running time 13 menit 18 detik. Berdasarkan pengujian Skenario 2 (klasifikasi menggunakan training data B), mesin mampu mengklasifikasikan testing data yang sama (gabungan semua parameter), dengan akurasi sebesar $88,70 \%$ dan running time 6 menit 34 detik. Berdasarkan hasil pengujian tersebut, maka dapat diketahui performa mesin lebih unggul ketika menggunakan training data B. Maka dari itu, dapat disimpulkan bahwa pola yang digunakan dalam penyusunan training data $B$ dinyatakan berhasil dan cocok untuk penelitian ini. Kemudian berdasarkan hasil analisis pengujian yang menunjukkan persentase prediksi opini positif lebih tinggi, maka dapat disimpulkan tweets masyarakat terhadap kinerja presiden dalam aspek ekonomi didominasi oleh opini positif.
\end{abstract}

Kata kunci: Naive Bayes Classifier, Opinion Mining, Tweets Masyarakat, Kinerja Presiden, Aspek Ekonomi

\section{Implementation of Naive Bayes Classifier on Opinion Mining Based on the Society Tweets Rjelated to Presidential Performance in Economy Aspect}

\begin{abstract}
Twitter is one of social media used as a means to get closer to the society. It can provide insight into what the society want. The purpose of this research is to produce a machine capable of classifying the society tweets related to presidential performance in economy aspect into positive and negative classes. The main aspects (economy) are reduced into "Indonesian economy", "employment" and "rupiah" parameters. Preprocessing texts used are cleaning, case folding, normalization, filtering, and stemming. This research applies scraping technique as tweets data collection technique, TF-IDF as word weighting method, Naive Bayes Classifier as classification algorithm, and Confusion Matrix as testing method. Training data consisted of training data A totaling 600 documents from tweets data and training data B totaling 158 documents based "parameter + independent word" pattern. Classification that is done by opinion mining machine as a whole (a combination of all parameters) can be stated as "Good Classification". Based on Scenario 1 testing (classification using training data
\end{abstract}


A), machine is able to classifying 540 testing data (combination of all parameters) with an accuracy of $87.96 \%$ and running time of 13 minutes 18 seconds. Based on Scenario 2 testing (classification using training data B), machine is able to classifying the same testing data (a combination of all parameters), with an accuracy of $88.70 \%$ and running time of 6 minutes 34 seconds. Based on results of tests, the machine's performance is superior when using training data B. Therefore, it can be concluded that the pattern used in preparation of training data B was declared successful and suitable for this research. Then based on results of the testing analysis which shows a higher percentage of positive opinion predictions, it can be concluded the society tweets on the performance of president in the economy aspect is dominated by positive opinions.

\section{Keywords: Naive Bayes Classifier, Opinion Mining, Society Tweets, Presidential Performance, Economy Aspect}

\section{Pendahuluan}

Presiden merupakan orang yang memimpin suatu negara, maka dari itu kinerja presiden dalam memimpin dan mengatasi permasalahan negara akan sangat berpengaruh pada kesejahteraan rakyatnya. Kesejahteraan rakyat erat kaitannya dengan aspek ekonomi, sebagaimana yang telah diketahui, ekonomi merupakan salah satu aspek penting dalam kehidupan bernegara, karena menyangkut keberlangsungan hidup seluruh rakyat Indonesia.

Hasil survei publik yang dilakukan oleh lembaga penelitian Indo Barometer pada tahun 2018 dengan pertanyaan "Permasalahan apa yang paling penting yang ada di Indonesia saat ini?", menunjukkan permasalahan "Perekonomian Rakyat" yang memiliki persentase paling teratas yang dipilih oleh publik, yakni 20,4\% [1]. Berdasarkan hasil survei tersebut, maka penelitian ini menganalisis opini masyarakat terkait permasalahan tersebut dengan memanfaatkan media sosial, yakni media sosial Twitter. Mengingat survei [2] yang menyatakan Indonesia adalah pengguna Twitter terbanyak ketiga di dunia, tentu tidak memungkinkan untuk menganalisis data tweets secara manual. Maka dari itu, pengimplementasian opinion mining atau yang biasa juga disebut dengan analisis sentimen adalah solusi dari permasalahan tersebut.

Opinion mining merupakan bidang studi yang menganalisis opini, sentimen, penilaian, sikap, dan emosi seseorang terhadap entitas dan atributnya, yang dinyatakan dalam teks tertulis. Opinion mining pada penelitian ini terdapat beberapa tahapan utama, yakni scraping data pada Twitter, text preprocessing, pembobotan menggunakan metode TF-IDF, pengklasifikasian menggunakan algoritma Naive Bayes Classifier, dan pengujian dengan confusion matrix.

Berdasarkan latar belakang permasalahan, rumusan masalah pada penelitian ini adalah bagaimana membangun opinion mining machine dengan mengimplementasikan algoritma Naive Bayes Classifier untuk mengklasifikasikan tweets masyarakat terkait kinerja presiden dalam aspek ekonomi ke dalam kelas positif dan negatif.

Tujuan dari penelitian ini adalah menghasilkan opinion mining machine dengan mengimplementasikan Naive Bayes Classifier sebagai algoritma pengklasifikasian, sehingga dapat mengklasifikasikan tweets masyarakat terkait kinerja presiden dalam aspek ekonomi, ke dalam kelas positif dan negatif.

Opinion mining machine yang dihasilkan dapat menjadi solusi untuk membantu proses analisis data tweets dengan mengklasifikasikan tweets masyarakat terkait kinerja presiden pada aspek ekonomi ke dalam kelas positif dan kelas negatif secara otomatis.

\section{MetodoloGi}

\section{A. Metodologi Penelitian}

Metodologi penelitian merupakan suatu perencanaan penelitian yang akan dilakukan secara sistematis dan ilmiah. Proses tersebut dilakukan dengan mendesain perencanaan penelitian sesuai dengan tahapan yang dilakukan pada penelitian. Metodologi penelitian tersebut diilustrasikan pada Gambar 1.

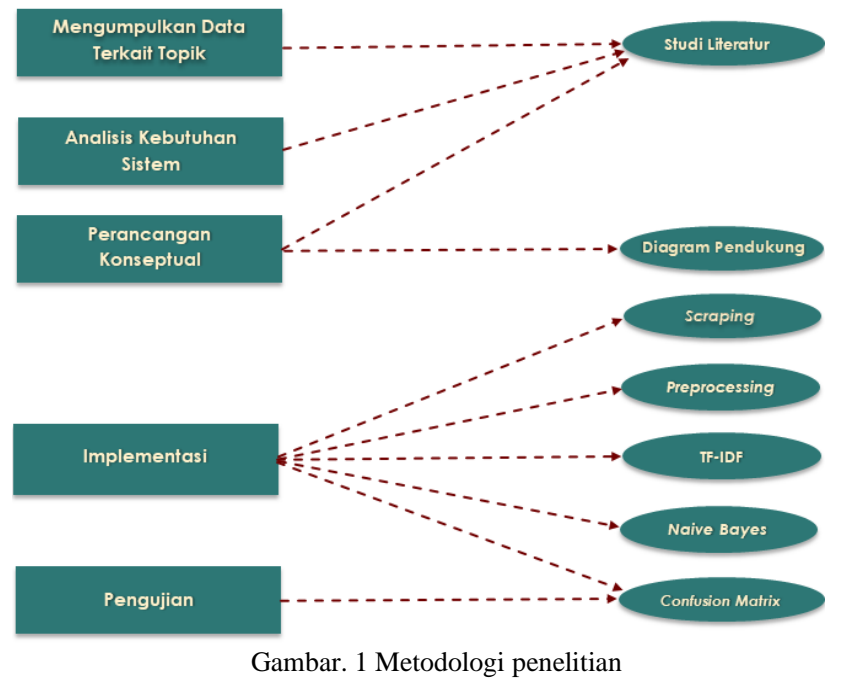

Tahapan pertama dalam penelitian yang dilakukan adalah mengumpulkan data terkait topik, yakni dengan melakukan studi literatur. Mengumpulkan referensi yang antara lain berasal dari buku, e-book, jurnal, website resmi, dan lain-lain. Menghasilkan studi ilmiah mengenai penelitian terkait, text mining, scraping, analisis sentimen (opinion mining), pembobotan (term weighting) TF-IDF, Naive Bayes Classifier, confusion matrix, bahasa pemrograman Python, media sosial Twitter, kinerja presiden, dan ekonomi.

Tahapan selanjutnya yakni melakukan analisis kebutuhan. Analisis kebutuhan dilakukan dengan menganalisis kembali hasil studi literatur, kemudian data yang telah diperoleh dari studi literatur tersebut dapat menjadi bahan untuk mengidentifikasi kebutuhan dalam penelitian. Pada tahap ini, dapat diidentifikasi antara lain dua komponen penting dalam penelitian ini yaitu kinerja presiden dan ekonomi. Kedua komponen tersebut menjadi fokus dalam penelitian ini. Selanjutnya, aspek ekonomi kemudian perlu diturunkan menjadi parameter yang lebih kecil yaitu "ekonomi indonesia", "lapangan pekerjaan" dan "rupiah" untuk memfokuskan penelitian. Penentuan parameter tersebut dibahas lebih lanjut pada poin A (Bab III). Kemudian berdasarkan hasil analisis, penelitian ini 
membutuhkan teknik scraping data sebagai teknik pengambilan data tweets, membutuhkan proses data selection secara manual agar mendapatkan tweets yang relevan dengan penelitian, membutuhkan tahap text preprocessing, pembobotan TF-IDF, pengklasifikasian menggunakan algoritma Naive Bayes Classifier, dan pengujian menggunakan metode confusion matrix.

Tahapan perancangan konseptual merupakan tahap untuk menjelaskan keterhubungan antar bagian dalam model klasifikasi yang dibangun menggunakan diagram pendukung berupa arsitektur sistem. Arsitektur sistem digunakan untuk menjelaskan rencana atau pemetaan dari proses-proses yang akan dilakukan dalam membangun opinion mining machine.

Tahapan selanjutnya dilakukan implementasi menggunakan bahasa pemrograman Python yang diawali dengan tahap pengambilan data menggunakan teknik scraping, text preprocessing, pembobotan menggunakan metode TF-IDF, pengklasifikasian menggunakan algoritma Naive Bayes Classifier, hingga tahap pengujian menggunakan metode confusion matrix.

Tahapan pengujian menggunakan confusion matrix dilakukan dengan beberapa parameter pengujian yakni accuracy, recall, precision, error rate, sensitivitas, dan spesifisitas. Kemudian hasil dari pengujian tersebut selanjutnya dilakukan analisis lebih lanjut untuk dapat ditarik kesimpulan.

\section{B. Studi Literatur}

\section{1) Penelitian Terkait}

Penelitian ini mengacu kepada dua penelitian terdahulu. Pertama, [3] melakukan penelitian tentang "Twitter Used by Indonesian President: A Sentiment Analysis of Timeline". Penggunaan metode Naive Bayes Classifier pada model yang dihasilkan pada penelitian ini bekerja baik dengan akurasi 79,42\% yang menunjukkan bahwa timeline @SBYudhoyono didominasi oleh sentimen netral. Kedua, [4] melakukan penelitian tentang "Analisis Sentimen Calon Gubernur DKI Jakarta 2017 di Twitter". Pada penelitian tersebut, metode klasifikasi Naive Bayes Classifier (NBC) lebih tinggi akurasinya dibandingkan dengan metode klasifikasi Support Vector Machine (SVM).

Berdasarkan beberapa penelitian tersebut, penelitian ini mengimplementasikan Naive Bayes Classifier pada opinion mining machine terkait kinerja presiden khususnya pada aspek ekonomi berdasarkan media sosial Twitter dengan beberapa hal yang membedakan yakni penelitian ini menggunakan bahasa pemrograman Python, menggunakan teknik scraping dalam pengambilan data, dan pengujian yang dilakukan menggunakan dua training data yang berbeda sebagai bahan perbandingan (training data A dan B). Training data A berasal dari tweets, sedangkan training data B disusun menggunakan pola "parameter + kata independen".

\section{2) Text Mining}

Text Mining dapat diartikan sebagai penambangan teks yang bertujuan untuk mendapatkan data berupa dokumen yang tidak terstruktur sehingga dapat dilakukan analisis agar dokumen menjadi terstruktur dan informasi dapat diperoleh dari dokumen tersebut [5]. Seperti halnya data mining, text mining juga menghadapi masalah yang sama, termasuk jumlah data yang besar, dimensi yang tinggi, data dan struktur yang terus berubah, dan data "noise". Berbeda dengan data mining yang utamanya memproses structured data, data yang digunakan text mining pada umumnya dalam bentuk unstructured, atau minimal semistructured data [6]. Akibatnya, text mining mempunyai tantangan tambahan yang tidak ditemui pada data mining, seperti struktur text yang complex dan tidak lengkap, arti yang tidak jelas dan tidak standar, serta bahasa yang berbeda ditambah translasi yang tidak akurat [7].

\section{3) Scraping}

Scraping adalah teknik yang saat ini menonjol untuk pengumpulan data online otomatis. Ini adalah salah satu teknik khas yang terkait dengan bentuk-bentuk penelitian sosial digital saat ini. Secara formal, scraping mengacu pada operasi teknis ekstraksi informasi, yang merupakan bidang yang berkaitan dengan pemrosesan data secara otomatis [8].

\section{4) Text Preprocessing}

Text preprocessing adalah suatu proses pengubahan bentuk data yang belum terstruktur menjadi data yang terstruktur sesuai dengan kebutuhan, untuk proses text mining lebih lanjut (sentiment analysis, peringkasan, clustering dokumen dan lain-lain) [9]. Text preprocessing diperlukan untuk menyelesaikan beberapa jenis masalah termasuk noisy data, data redundansi, nilai data yang hilang, dan lain-lain [10].

Adapun tahapan text preprocessing pada penelitian ini yakni cleaning, case folding, normalisasi, filtering, dan stemming, yang dijelaskan pada poin-poin berikut ini.

a. Cleaning merupakan proses membersihkan tweets dari simbol, karakter, dan sebagainya yang tidak diperlukan untuk mengurangi data noise [7].

b. Case folding merupakan proses mengubah semua huruf dalam suatu dokumen atau kalimat menjadi huruf kecil [11]. Case folding digunakan untuk mempermudah pencarian. Tidak semua data konsisten dalam penggunaan huruf kapital.

c. Normalisasi teks berfungsi untuk memperbaiki katakata yang kurang tepat penulisannya di dalam teks [7].

d. Filtering merupakan suatu proses untuk menghilangkan bagian-bagian dari dokumen mentah yang tidak mempunyai relevansi atau tidak memiliki arti bagi proses klasifikasi [12].

e. Stemming adalah proses pengubahan bentuk kata menjadi kata dasar atau tahap mencari root kata dari tiap kata. Pada proses stemming, setiap kata berimbuhan akan berubah menjadi kata dasar, dengan demikian dapat lebih mengoptimalkan proses text mining [9].

\section{5) Opinion Mining}

Opinion mining yang juga disebut analisis sentimen merupakan salah satu cabang penelitian text mining. Opinion mining adalah bidang studi yang menganalisis opini, sentimen, penilaian, sikap, dan emosi seseorang 
terhadap entitas dan atributnya yang dinyatakan dalam teks tertulis. Entitas dapat berupa produk, layanan, organisasi, individu, peristiwa, masalah, atau topik [13].

\section{6) Term Frequency - Inverse Document Frequency}

Metode Term Frequency - Inverse Document Frequency (TF-IDF) merupakan suatu cara untuk memperoleh pembobotan berdasarkan jumlah kemunculan suatu kata (term) dalam sebuah dokumen dan dalam keseluruhan dokumen [14]. Nilai TF-IDF diperoleh setelah nilai TF dan IDF dihitung terlebih dahulu. Kemudian kedua nilai tersebut dikalikan untuk mendapatkan nilai TF-IDF [15].

\section{7) Naive Bayes Classifier}

Naive Bayes Classifier yang disingkat NBC merupakan algoritma yang digunakan untuk mencari nilai probabilitas tertinggi untuk mengklasifikasikan data uji pada kategori yang paling tepat [ 16].

Klasifikasi ini merupakan klasifikasi yang bersifat supervised learning karena memiliki supervisor (manusia melakukan klasifikasi secara manual pada data yang digunakan dalam pelatihan) selaku pengajar dalam proses belajar atau learning. Ciri utama dari NBC ini adalah asumsi yang sangat kuat (naif) akan independensi dari masing-masing kondisi/kejadian. NBC mengasumsikan variabel independen, maka hanya varians dari suatu variabel dalam sebuah kelas yang dibutuhkan untuk menentukan klasifikasi, bukan keseluruhan dari matriks kovarians [17].

Naive Bayes ada tiga jenis menurut distribusi fitur, yaitu Gaussian Naive Bayes, Multinomial Naive Bayes, dan Bernoulli Naive Bayes. Tetapi algoritma Naive Bayes yang sering digunakan untuk text mining adalah Multinomial Naive Bayes [18]. Pada Naive Bayes Classifier, untuk menghindari peluang 0 yang terjadi pada training yang akan menghancurkan hasil testing nantinya, diperlukan laplace smoothing [15].

\section{8) Confusion Matrix}

Confusion matrix adalah tool yang digunakan sebagai evaluasi model klasifikasi untuk memperkirakan objek yang benar atau salah. Sebuah matrix dari prediksi yang akan dibandingkan dengan kelas sebenarnya atau dengan kata lain berisi informasi nilai sebenarnya dan prediksi pada klasifikasi [19]. Tabel confusion matrix dapat dilihat pada Tabel 1 berikut.
TABEL I

CONFUSION MATRIX

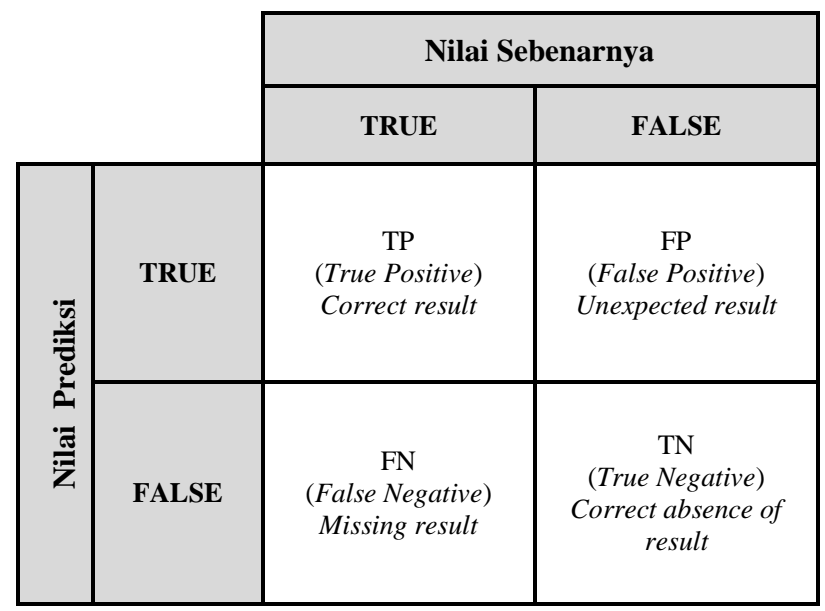

Parameter pengukuran digunakan untuk mengevaluasi performansi dari model yang telah dibuat. Metode Text Classification bisa dievaluasi dengan menggunakan accuracy, precision, dan recall [20].

Akurasi didefinisikan sebagai tingkat kedekatan antara nilai prediksi dan nilai aktual. Precision adalah tingkat ketepatan antara informasi yang diminta oleh pengguna dengan jawaban yang diberikan oleh sistem. Sedangkan Recall adalah persentase keberhasilan sistem dalam menemukan kembali sebuah informasi [20]. Rumus untuk menghitung akurasi, precision, dan recall adalah sebagai berikut:

$$
\begin{aligned}
\text { Akurasi } & =\frac{T P+T N}{T P+T N+F P+F N} \\
\text { Precision } & =\frac{T P}{T P+F P} \\
\text { Recall } & =\frac{T P}{T P+F N}
\end{aligned}
$$

Rumus untuk menghitung error rate pada confusion matrix adalah sebagai berikut:

Error Rate $=\frac{F N+F N}{T P+T N+F P+F N}$

Rumus untuk menghitung spesifisitas dan sensitivitas pada confusion matrix adalah sebagai berikut:

$$
\begin{aligned}
& \text { Sensitivitas }=\frac{T P}{T P+F N} \\
& \text { Spesifisitas }=\frac{T N}{T N+F P}
\end{aligned}
$$

\section{9) Bahasa Pemrograman Python}

Python merupakan bahasa pemrograman tingkat tinggi. Hal ini disebabkan karena kode yang dituliskan akan di compile menjadi byte code dan dieksekusi sehingga Python cocok digunakan untuk 
scripting language, aplikasi web dan lain sebagainya. Hal lain yang menjadikan bahasa ini menjadi bahasa pemgrograman tingkat tinggi adalah Python dapat di extend ke dalam bahasa $\mathrm{C}$ dan $\mathrm{C}++$ serta bahasa pemrograman ini memiliki struktur konstruksi yang kuat (blok kode, fungsi, class, modules, dan packages) dan serta konsisten menggunakan konsep Object Oriented Programming (OOP) [21].

\section{0) Twitter}

Twitter adalah sebuah situs web yang dimiliki dan dioperasikan oleh Twitter Inc., yang menawarkan jaringan sosial berupa mikroblog sehingga memungkinkan penggunanya untuk mengirim dan membaca pesan yang disebut kicauan (tweets). Tweets adalah teks tulisan hingga 140 karakter yang ditampilkan pada halaman profil pengguna. Kicauan bisa dilihat secara luas, namun pengirim dapat membatasi pengiriman pesan ke daftar teman-teman mereka saja. Pengguna dapat melihat kicauan penulis lain yang dikenal dengan sebutan pengikut [22].

\section{1)Kinerja Presiden}

Kinerja merujuk kepada tingkat keberhasilan dalam melaksanakan tugas serta kemampuan untuk mencapai tujuan yang telah ditetapkan. Kinerja dinyatakan baik dan sukses jika tujuan yang diinginkan dapat tercapai dengan baik [23].

\section{2)Ekonomi}

Menurut hasil survei publik yang dilakukan oleh lembaga penelitian Indo Barometer dengan pertanyaan "Permasalahan apa yang paling penting yang ada di Indonesia saat ini?", permasalahan "Perekonomian Rakyat" memiliki persentase paling teratas yang dipilih oleh publik, yakni $20,4 \%[1]$.

Sistem perekonomian yang berlaku di Indonesia disebut juga dengan demokrasi ekonomi. Dalam demokrasi ekonomi, semua kegiatan perekonomian harus lebih mengutamakan pada kesejahteraan dan kemakmuran rakyat yang dapat dirasakan secara merata oleh seluruh rakyat, dan untuk mewujudkannya menuntut partisipasi aktif dari seluruh rakyat dalam kegiatan perekonomian [24].

\section{Arsitektur Sistem}

Arsitektur sistem digunakan untuk menjelaskan rencana atau pemetaan dari proses-proses yang akan dilakukan dalam membangun opinion mining machine. Hasil perancangan arsitektur sistem dapat dilihat pada Gambar 2.

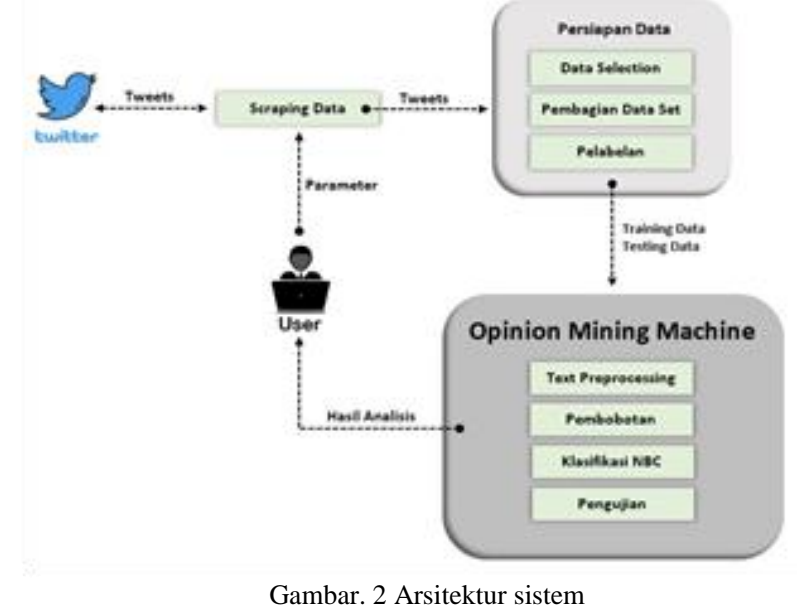

Gambar 2 merupakan arsitektur sistem pada penelitian ini. Langkah pertama, user melakukan scraping data pada Twitter dengan menginputkan parameter (keywords) kinerja presiden yang telah ditentukan pada source code yang digunakan untuk request data tweets pada Twitter pada rentang waktu yang diinginkan. Data tweets hasil scraping kemudian dilakukan persiapan data seperti data selection, pembagian data set, dan pelabelan. Sehingga dari proses tersebut, terbentuk training dan testing data yang siap untuk diolah oleh mesin. Pada mesin, training dan testing data tersebut dilakukan tahapan-tahapan penting opinion mining, dimulai dari text preprocessing, pembobotan menggunakan metode TF-IDF, klasifikasi dengan algoritma Naive Bayes Classifier, hingga tahap pengujian untuk mengetahui nilai akurasi, error rate, dan parameter pengujian lainnya. Sehingga, user dapat mengetahui hasil analisis (hasil prediksi opini dan hasil pengujian) dari data yang telah diolah oleh mesin. Tahapan-tahapan yang digambarkan pada arsitektur sistem dijelaskan pada poin-poin berikut.

\section{1) Scraping Data}

Pengumpulan data dilakukan dengan teknik scraping data pada media sosial Twitter. Scraping adalah teknik yang dilakukan untuk memperoleh data dari sebuah sumber data tanpa batas, dimana dalam penelitian ini Twitter merupakan sumber data tersebut.

Data tweets yang telah diperoleh pada Januari 2018 Maret 2019, terbagi menjadi training data yang diambil dari tahun 2018 dan testing data yang diambil dari tahun 2019. Pada tahun tersebut merupakan waktu yang tepat untuk memperoleh penilaian atau tanggapan dari masyarakat tentang program-program pemerintah yang sudah berjalan cukup lama sejak presiden tersebut dilantik. Untuk mengambil data pada jangka waktu yang cukup panjang tersebut dibutuhkan teknik scraping data, yang dapat memperoleh data tanpa batasan waktu ataupun batasan jumlah tweets.

Proses scraping data membutuhkan library khusus pada bahasa pemrograman Python, yakni library Twitterscraper. Kemudian, data tweets yang berhasil diperoleh dari proses tersebut akan tersimpan dalam format .csv. 


\section{2) Data Selection}

Data tweets hasil scraping membutuhkan penanganan lebih lanjut sebelum dilakukan pelabelan, karena tweets hasil scraping ketahui masih sangat bias dan masih terdapat data redundansi. Sangat bias misalnya ditemukan dalam keyword ekonomi ternyata dijumpai pada beberapa kasus lain selain kinerja presiden. Data redundansi misalnya tweets yang sama dilakukan posting lebih dari satu kali pada akun yang sama. Untuk mengatasi hal tersebut, dibutuhkan tahapan data selection dengan bantuan microsoft excel untuk menyeleksi kembali data hasil scraping agar dapat mengatasi data redundansi dan mendapatkan tweets yang relevan dengan topik yang diangkat dalam penelitian.

\section{3) Pelabelan}

Training data dan testing data yang telah disiapkan selanjutnya perlu dilakukan pelabelan untuk tujuan yang berbeda. Pelabelan merupakan tahap pemberian label pada data tweets yang sudah diseleksi, dengan cara memberi label "positif" atau "negatif" sesuai makna dari tweets tersebut secara manual oleh peneliti. Kelas positif ditentukan dari isi tweets yang mengandung kata bermakna positif, seperti kata "meningkat", "maju", "berkembang", dan sebagainya Sedangkan kelas negatif ditentukan dari isi tweets yang mengandung kata bermakna negatif, seperti menurun, sulit, lemah, memburuk, dan sebagainya.

\section{4) Text Preprocessing}

Data tweets yang diperoleh dari tahap sebelumnya merupakan data yang belum terstruktur, karena tweets yang diperoleh biasanya terdapat noisy data seperti alamat situs (URL/link), mention (@username), hashtag (\#), angka, karakter, tanda baca, dll, termasuk kata-kata yang kurang penting untuk klasifikasi. Maka dari itu, dibutuhkan tahap text preprocessing, yang berfungsi untuk membersihkan data tweets agar sistem dapat lebih mudah dalam melakukan komputerisasi data dan mereduksi kata yang kurang penting.

\section{5) Pembobotan TF-IDF}

Data yang telah melalui tahap text preprocessing harus berbentuk numerik. Maka dibutuhkan sebuah metode pembobotan yakni Term Frequency - Inverse Document Frequency (TF-IDF) untuk mengubah teks (kata) pada data yang digunakan menjadi bobot-bobot angka, agar dapat diolah oleh Naive Bayes Classifier. Pembobotan yang dilakukan yakni berdasarkan frekuensi kemunculan suatu kata (term) dalam sebuah dokumen (TF) dan frekuensi kemunculan suatu kata (term) dalam kumpulan dokumen (IDF).

\section{6) Klasifikasi Naive Bayes Classifier}

NBC memiliki asumsi yang sangat kuat (naif) akan independensi dari masing-masing kondisi/kejadian. Berdasarkan hasil analisis, dapat diketahui variabel independen dalam NBC merupakan variabel yang mempengaruhi, dan variabel dependen yakni variabel yang dipengaruhi. Dapat diambil contoh pada kalimat "ekonomi indonesia stabil" maka kata "stabil" merupakan kata independen sedangkan "ekonomi indonesia" merupakan kata dependen.

\section{7) Pengujian}

Dalam menguji performa pengklasifikasian yang dihasilkan mesin, dibutuhkan sebuah metode pengujian, yakni dengan menggunakan metode confusion matrix. Confusion matrix merupakan sebuah matrix yang berisi informasi nilai sebenarnya (klasifikasi manual) dan prediksi pada klasifikasi yang dilakukan oleh mesin. Pengujian dapat dilakukan dengan beberapa parameter pengujian, yang pada penelitian ini yakni accuracy, recall, precision, error rate, sensitivitas dan spesifisitas.

\section{HASIL DAN PEMBAHASAN}

\section{A. Identifikasi Parameter Kinerja Presiden}

Aspek ekonomi diturunkan menjadi beberapa parameter agar lebih memfokuskan opinion mining yang dilakukan, yaitu "ekonomi indonesia", "lapangan pekerjaan" dan "rupiah". Parameter "ekonomi Indonesia" dipilih karena mampu menggambarkan kondisi perekonomian di Indonesia secara keseluruhan termasuk perekonomian rakyat. Kemudian parameter "lapangan pekerjaan" dipilih karena, [24] menyatakan sistem perekonomian yang berlaku di Indonesia disebut juga dengan demokrasi ekonomi yang mana salah satu cirinya adalah warga negara memiliki kebebasan dalam memilih pekerjaan yang dikehendaki dan mempunyai hak akan pekerjaan dan penghidupan yang layak. Kemudian parameter "rupiah" dipilih karena, peran rupiah sangat berpengaruh bagi harga barang dan jasa. Jika nilai tukar rupiah stabil maka harga barang dan jasa juga stabil, hal itu tentunya berdampak pada stabilitas perekonomian Indonesia.

Penentuan parameter juga ditentukan berdasarkan kecenderungan makna kata (kata independen) yang sama ketika dibahasakan dalam tweets yang bersifat penilaian terhadap kinerja presiden, sehingga setelah dilakukan analisis, parameter "ekonomi Indonesia", "lapangan pekerjaan", dan "rupiah" memiliki kesamaan dalam kecenderungan makna kata (kata independen) ketika dibahasakan dalam kalimat (tweets) yang bersifat penilai terhadap kinerja presiden.

Sebagai contoh, untuk mengklasifikasikan tweets terkait "ekonomi Indonesia" sebagai opini positif diperlukan kata independen antara lain seperti kata "naik", "meningkat" dan sebagainya pada kalimat tweets tersebut, begitu juga dengan tweets terkait "lapangan pekerjaan" dan "rupiah", ketika terdapat kata independen "naik", atau "meningkat" pada kalimat tweets tersebut, tweets tersebut juga dapat diklasifikasikan sebagai opini positif, bukan sebaliknya. Ketika setiap parameter tersebut disandingkan dengan kata independen berkonotasi negatif dalam hal ini antara lain seperti "menurun", dan 
"melemah", setiap parameter juga akan menghasil kecenderungan makna kata yang sama untuk ketiganya, yakni akan menghasilkan kalimat bermakna negatif.

\section{B. Gambaran Umum Opinion Mining}

Berdasarkan analisis yang telah dilakukan, terdapat beberapa proses dan output yang menggambarkan penelitian ini secara keseluruhan, yang divisualisasikan pada Gambar 3 berikut ini.

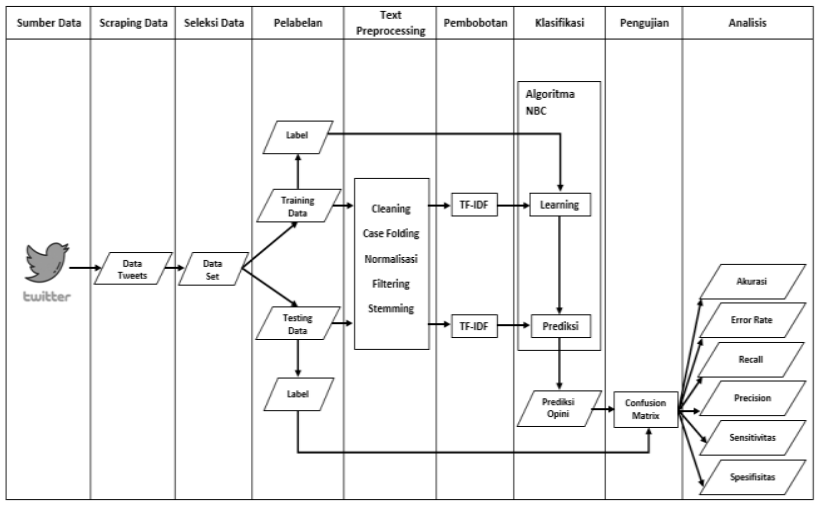

Gambar. 3 Gambaran umum opinion mining

Gambar 3 di atas adalah gambaran penelitian secara keseluruhan terkait proses dan output. Sumber data yang digunakan berasal dari media sosial Twitter, dimana proses pengambilan data dilakukan dengan teknik scraping sehingga menghasilkan output berupa data tweets. Selanjutnya data tweets tersebut dilakukan proses data selection untuk mendapatkan tweets yang relevan dengan penelitian sehingga mendapatkan output berupa data set, yang selanjutnya data tersebut dibagi menjadi training data dan testing data. Training data dilakukan pelabelan, text preprocessing, dan pembobotan menggunakan metode TF-IDF, sehingga dari bobot yang dihasilkan tersebut selanjutnya diolah menggunakan algoritma NBC untuk proses pembelajaran mesin. Kemudian, testing data juga dilakukan pelabelan, text preprocessing, dan pembobotan menggunakan metode TF-IDF, sehingga dari bobot yang dihasilkan tersebut dapat dilakukan tahap selanjutnya yakni tahap memprediksi opini dengan algoritma NBC berdasarkan pembelajaran mesin yang telah dilakukan sebelumnya, sehingga menghasilkan output berupa klasifikasi prediksi opini. Hasil klasifikasi tersebut kemudian dilakukan pengujian menggunakan metode confusion matrix untuk menguji performansi mesin. Pada tahap ini data label dari testing data yang telah dilakukan sebelumnya menjadi acuan untuk mengetahui nilai akurasi, error rate, dan parameter pengujian lainnya.

\section{Twitter Scraping}

Perolehan tweets hasil scraping dapat dilihat pada Tabel 2 berikut ini.
TABEL II

Perolehan TweEts

\begin{tabular}{|c|c|c|}
\hline \multirow{2}{*}{ Parameter } & \multicolumn{2}{|c|}{ Perolehan Tweets Hasil Scraping } \\
\cline { 2 - 3 } & $\begin{array}{c}\text { Training Data } \\
\text { (Jan-Des 2018) }\end{array}$ & $\begin{array}{c}\text { Testing Data } \\
\text { (Jan-Mar 2019) }\end{array}$ \\
\hline Ekonomi Indonesia & 9639 & 1599 \\
\hline Lapangan Pekerjaan & 8438 & 1047 \\
\hline Rupiah & 6420 & 1626 \\
\hline Total Tweets & 24497 & 4272 \\
\hline
\end{tabular}

Data yang didapatkan tersebut merupakan data yang bias dan banyak terdapat redundansi data, maka dari itu data tweets tersebut dilakukan tahap data selection yang dilakukan secara manual, sehingga didapatkan data set untuk training dan testing data..

\section{Data Set}

Jumlah training data dalam sistem analisis sentimen memiliki pengaruh terhadap prediksi sistem. Selain jumlah, kualitas data latih juga berperan karena semakin tinggi kualitas data maka sistem akan mendapatkan vocabulary yang semakin besar sehingga akan lebih tepat dalam memprediksi kelas sentimen [25].

Penelitian ini menggunakan dua training data, yaitu training data $\mathrm{A}$ dan training data $\mathrm{B}$, tujuannya adalah untuk membandingkan hasil klasifikasi mesin ketika menggunakan training data $\mathrm{A}$ dan training data $\mathrm{B}$, sehingga diketahui pada penggunaan training data mana yang menghasilkan performa lebih baik.

Training data A adalah training data yang berjumlah lebih banyak dibandingkan training data $\mathrm{B}$ dan memiliki sebaran jumlah dokumen yang merata antar parameter. Training data A diambil dari data tweets pada Januari Desember tahun 2018, yang berjumlah 600 tweets. Terdiri dari 100 tweets positif dan 100 tweets negatif untuk setiap parameter.

Training data $\mathrm{B}$ disusun oleh peneliti menggunakan pola "parameter + kata independen", dimana pola tersebut dapat bertukar posisi menyesuaikan konteks kalimat. Kata independen yang digunakan berdasarkan hasil analisis pada data scraping. Training data B merupakan training data yang jumlahnya lebih sedikit dan lebih singkat dibandingkan training data $\mathrm{A}$, dan memiliki sebaran jumlah dokumen yang tidak merata antar parameter. Training data B berjumlah 158 dokumen, yakni terdiri dari 40 dokumen positif maupun negatif untuk parameter "ekonomi Indonesia", 24 dokumen positif maupun negatif untuk parameter "lapangan pekerjaan", dan 15 dokumen positif maupun negatif untuk parameter "rupiah".

Testing data menggunakan data tweets pada bulan Januari - Maret tahun 2019 dengan total 540 opini publik, jumlah data yang digunakan tersebut ditentukan berdasarkan jumlah data relevan yang didapat. 
Sebaran dokumen pada training data A, training data B dan testing data dapat dilihat pada Tabel 3.

TABEL III

SEBARAN DOKUMEN

\begin{tabular}{|c|c|c|c|}
\hline \multirow{2}{*}{ Parameter } & \multicolumn{3}{|c|}{ Jumlah Dokumen } \\
\cline { 2 - 4 } & $\begin{array}{c}\text { Training } \\
\text { Data A }\end{array}$ & $\begin{array}{c}\text { Training } \\
\text { Data B }\end{array}$ & $\begin{array}{c}\text { Testing } \\
\text { Data }\end{array}$ \\
\hline Ekonomi Indonesia & 200 & 80 & 216 \\
\hline Lapangan Pekerjaan & 200 & 48 & 205 \\
\hline Rupiah & 200 & 30 & 119 \\
\hline Total Dokumen & $\mathbf{6 0 0}$ & $\mathbf{1 5 8}$ & $\mathbf{5 4 0}$ \\
\hline
\end{tabular}

\section{E. Pelabelan}

Tahap pelabelan adalah tahap pemberian label pada dokumen (tweets) yang telah diperoleh dari hasil Twitter scraping dan telah melewati proses data selection. Pelabelan dilakukan dengan cara memberi label "positif" atau "negatif" sesuai kategori tweets tersebut secara manual pada data tweets yang sudah diseleksi.

Dokumen yang telah dilabel dalam bentuk file .csv dapat dilihat pada Gambar 4 berikut ini.

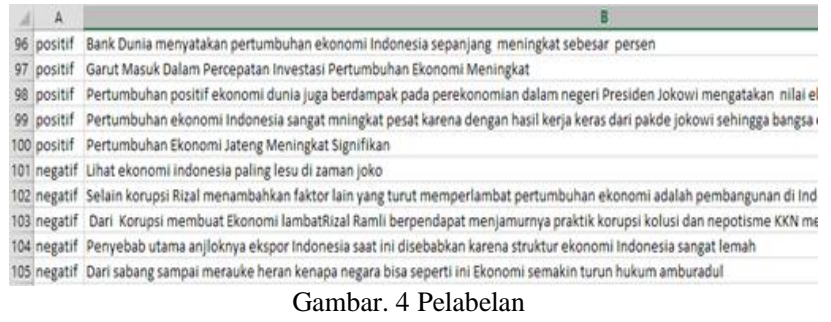

\section{F. $\quad$ Text Preprocessing}

Setelah dilakukan pelabelan pada tahap sebelumnya, training data dan testing data kemudian dilakukan text preprocessing. Tahapan text preprocessing yang dilakukan yakni cleaning, case folding, normalisasi, filtering, dan stemming, seperti yang ditampilkan pada Gambar 5 berikut ini.
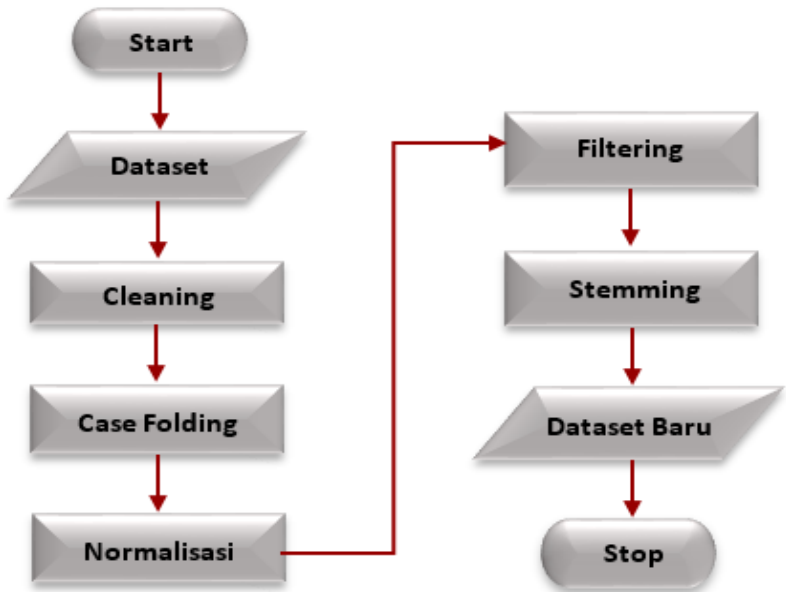

Gambar. 5 Text preprocessing
Hasil implementasi dari keseluruhan tahapan text preprocessing pada suatu dokumen, dituangkan dalam bentuk tabel dan dalam bentuk keluaran dari mesin. Contoh hasil text preprocessing dalam bentuk tabel yakni sebagai berikut.

TABEL IV

HASIL TEXT PREPROCESSING

\begin{tabular}{|l|c|}
\hline \multicolumn{1}{|c|}{ Dokumen } & Text Preprocessing \\
\hline $\begin{array}{l}\text { asal kalian tahu, EMPAT Tahun Terakhir } \\
\text { Ekonomi Indonesia Membaik berkat krj } \\
\text { @jokowi ! Pemerintah tidak gagal \#kerja } \\
\text { http://share.babe.news/s/xdSYNpdÂ }\end{array}$ & Original \\
\hline $\begin{array}{l}\text { asal kalian tahu EMPAT Tahun Terakhir } \\
\text { Ekonomi Indonesia Membaik berkat krj } \\
\text { Pemerintah tidak gagal }\end{array}$ & Cleaning \\
\hline $\begin{array}{l}\text { asal kalian tahu empat tahun terakhir } \\
\text { ekonomi indonesia membaik berkat krj } \\
\text { pemerintah tidak gagal }\end{array}$ & Case Folding \\
\hline $\begin{array}{l}\text { asal kalian tahu empat tahun terakhir } \\
\text { ekonomi indonesia membaik berkat kerja } \\
\text { pemerintah berhasil }\end{array}$ & Normalisasi \\
\hline $\begin{array}{l}\text { tahun ekonomi indonesia membaik kerja } \\
\text { pemerintah berhasil }\end{array}$ & Filtering \\
\hline $\begin{array}{l}\text { tahun ekonomi indonesia baik kerja perintah } \\
\text { berhasil }\end{array}$ & Stemming \\
\hline
\end{tabular}

Adapun hasil keluaran dari keseluruhan proses text preprocessing oleh mesin pada dokumen yang sama pada Tabel 4 dapat dilihat pada Gambar 6 berikut ini.

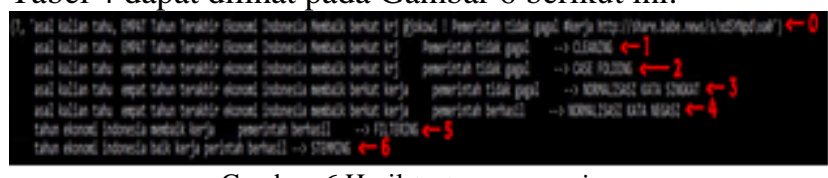

Gambar. 6 Hasil text preprocessing

Pada Gambar 6, dapat dilihat terdapat keterangan dengan nomor $0,1,2,3,4,5$, dan 6 .

Nomor 0 merupakan original tweet yang belum dilakukan preprocessing. Keterangan pada nomor 1 merupakan keluaran dari hasil cleaning dimana tanda baca, @username, \#hashtag, dan URL yang terdapat pada dokumen telah dibersihkan. Keterangan pada nomor 2 merupakan keluaran dari hasil case folding, dimana semua huruf yang terdapat pada dokumen telah diseragamkan menjadi huruf kecil (lowercase). Keterangan pada nomor 3 merupakan keluaran dari hasil normalisasi untuk kata singkat, dimana kata singkat yang terdapat pada dokumen telah disempurnakan menjadi kata yang seharusnya. Keterangan pada nomor 4 merupakan keluaran dari hasil normalisasi kata negasi, dimana kata independen yang diikuti kata negasi akan dinormalisasi dengan mengganti kata yang bermakna sama. Keterangan pada nomor 5 merupakan keluaran dari hasil filtering, dimana kata-kata yang tidak penting seperti kata ganti, kata keterangan, kata sambung, kata depan dan kata sandang 
dihilangkan. Keterangan pada nomor 6 merupakan keluaran dari hasil stemming, dengan mengembalikan kata-kata yang terdapat pada dokumen ke bentuk akar kata (kata dasar).

\section{G. Pembobotan TF-IDF}

Hasil text preprocessing kemudian dilakukan tahap pembobotan agar kemudian dapat dilakukan tahap klasifikasi. Hasil keluaran dari tahap pembobotan menggunakan metode TF-IDF dapat dilihat pada Gambar 7.

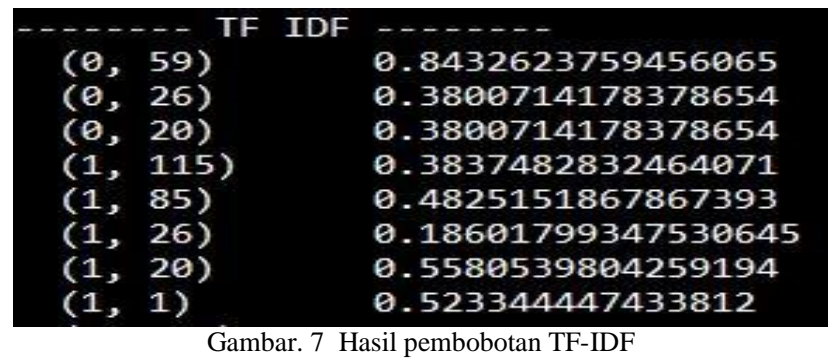

Output pada Gambar 7 tersebut adalah bobot-bobot angka yang dihasilkan dari mesin yang kemudian dilanjutkan ke tahap klasifikasi.

\section{H. Klasifikasi Naive Bayes}

Hasil dari implementasi metode Naive Bayes Classifier yang dilakukan pada opinion mining machine dapat dilihat pada Gambar 8.

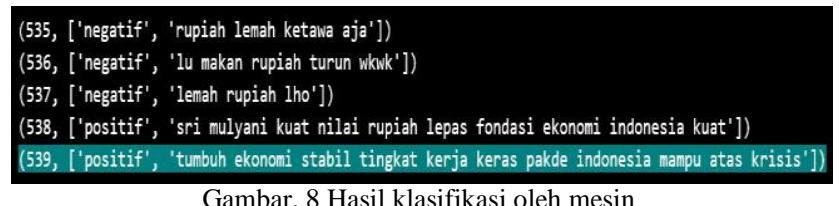

Gambar 8 diatas merupakan hasil prediksi dari testing data yang digunakan yang selanjutnya dilakukan pengujian untuk mengetahui akurasi, dan parameter pengujian lainnya.

\section{Pengujian}

Pengujian dilakukan dengan dua skenario pengujian, skenario pengujian pertama dilakukan dengan training data A yang berasal dari data tweets yang berjumlah 600 dokumen dengan sebaran jumlah dokumen yang merata pada setiap parameter. Sedangkan untuk skenario pengujian kedua, menggunakan training data B yang disusun berdasarkan pola "parameter + kata independen", yang berjumlah 158 dokumen dengan sebaran jumlah dokumen yang tidak merata pada masing-masing parameter.

Pengujian dilakukan dengan menggunakan parameter pengujian akurasi, error rate, precision, recall, sensitivitas, dan spesifisitas.

Hasil pengujian pada Tabel 5 dibawah merupakan tabel hasil pengujian pada masing-masing parameter ("ekonomi Indonesia", "lapangan pekerjaan" dan "rupiah") dan pengujian pada keseluruhan testing data (gabungan semua parameter) dengan total 540 dokumen. Hasil pengujian dapat dilihat pada Tabel 5 berikut ini.
TABEL V

HASIL PENGUJiAN

\begin{tabular}{|c|c|c|c|}
\hline $\begin{array}{c}\text { Parameter } \\
\text { Penilaian }\end{array}$ & $\begin{array}{l}\text { Parameter } \\
\text { Pengujian }\end{array}$ & Skenario 1 & Skenario 2 \\
\hline \multirow{6}{*}{$\frac{\text { Ekonomi }}{\underline{\text { Indonesia }}}$} & TP & 153 & 160 \\
\hline & $\mathbf{F N}$ & 8 & 1 \\
\hline & $\mathbf{T N}$ & 42 & 42 \\
\hline & FP & 13 & 13 \\
\hline & Accuracy & $90.28 \%$ & $93.52 \%$ \\
\hline & Error Rate & $9.72 \%$ & $6.48 \%$ \\
\hline \multirow{7}{*}{$\begin{array}{c}\text { Data Aktual: } \\
\text { Total Opini } 216 \\
\text { Opini Positif } 161 \\
\text { Opini Negatif } 55\end{array}$} & Precision & $92.17 \%$ & $92.49 \%$ \\
\hline & Recall & $95.03 \%$ & $99.38 \%$ \\
\hline & Sensitivitas & $95.03 \%$ & $99.38 \%$ \\
\hline & Spesifisitas & $76.36 \%$ & $76.36 \%$ \\
\hline & Running Time & $08 \mathrm{~m} \mathrm{06d}$ & $03 \mathrm{~m} \mathrm{05d}$ \\
\hline & $\begin{array}{r}\text { Prediksi } \\
\text { Opini Positif }\end{array}$ & $166=76.85 \%$ & $173=80.09 \%$ \\
\hline & $\begin{array}{r}\text { Prediksi } \\
\text { Opini Negatif }\end{array}$ & $50=23.15 \%$ & $43=19.91 \%$ \\
\hline \multirow{7}{*}{$\frac{\text { Lapangan }}{\text { Pekerjaan }}$} & TP & 67 & 78 \\
\hline & FN & 26 & 15 \\
\hline & TN & 100 & 81 \\
\hline & $\mathbf{F P}$ & 12 & 31 \\
\hline & Accuracy & $81.46 \%$ & $77.56 \%$ \\
\hline & Error Rate & $18.54 \%$ & $22.44 \%$ \\
\hline & Precision & $84.81 \%$ & $71.56 \%$ \\
\hline \multirow{6}{*}{$\begin{array}{c}\text { Data Aktual: } \\
\text { Total Opini } 205 \\
\text { Opini Positif } 93 \\
\text { Opini Negatif } \\
112\end{array}$} & Recall & $72.04 \%$ & $83.87 \%$ \\
\hline & Sensitivitas & $72.04 \%$ & $83.87 \%$ \\
\hline & Spesifisitas & $89.29 \%$ & $72.32 \%$ \\
\hline & Running Time & $07 \mathrm{~m} \mathrm{50d}$ & $03 \mathrm{~m} 27 \mathrm{~d}$ \\
\hline & $\begin{array}{r}\text { Prediksi } \\
\text { Opini Positif }\end{array}$ & $79=38.54 \%$ & $109=53.17 \%$ \\
\hline & $\begin{array}{r}\text { Prediksi } \\
\text { Opini Negatif } \\
\end{array}$ & $126=61.46 \%$ & $96=46.83 \%$ \\
\hline \multirow{13}{*}{$\begin{array}{l}\text { Total } \\
\text { Opini } \\
\text { Opini I }\end{array}$} & $\overline{T P}$ & 80 & 82 \\
\hline & FN & 2 & $\overline{0}$ \\
\hline & TN & 33 & 36 \\
\hline & FP & 4 & 1 \\
\hline & Accuracy & $94.96 \%$ & $99.16 \%$ \\
\hline & Error Rate & $5.04 \%$ & $0.84 \%$ \\
\hline & Precision & $95.24 \%$ & $98.80 \%$ \\
\hline & Recall & $97.56 \%$ & $100 \%$ \\
\hline & Sensitivitas & $97.56 \%$ & $100 \%$ \\
\hline & Spesifisitas & $89.19 \%$ & $97.30 \%$ \\
\hline & Running Time & $06 \mathrm{~m} \mathrm{09d}$ & $01 \mathrm{~m} 13 \mathrm{~d}$ \\
\hline & $\begin{array}{r}\text { Prediksi } \\
\text { Opini Positif }\end{array}$ & $84=70.58 \%$ & $83=69.75 \%$ \\
\hline & $\begin{array}{r}\text { Prediksi } \\
\text { Opini Negatif }\end{array}$ & $35=29.41 \%$ & $36=30.25 \%$ \\
\hline \multirow{7}{*}{$\begin{array}{l}\frac{\text { Gabungan }}{\text { Semua }} \\
\text { Parameter }\end{array}$} & TP & 300 & 320 \\
\hline & FN & 36 & 16 \\
\hline & TN & 175 & 159 \\
\hline & $\mathbf{F P}$ & 29 & 45 \\
\hline & Accuracy & $87.96 \%$ & $88.70 \%$ \\
\hline & Error Rate & $12.03 \%$ & $11.30 \%$ \\
\hline & Precision & $91.18 \%$ & $87.67 \%$ \\
\hline \multirow{6}{*}{$\begin{array}{c}\text { Data Aktual } \\
\text { Total Opini } 540 \\
\text { Opini Positif } 336 \\
\text { Opini Negatif } \\
204\end{array}$} & Recall & $89.28 \%$ & $95.24 \%$ \\
\hline & Sensitivitas & $89.28 \%$ & $95.24 \%$ \\
\hline & Spesifisitas & $85.78 \%$ & $77.94 \%$ \\
\hline & Running Time & $13 \mathrm{~m} 18 \mathrm{~d}$ & $06 \mathrm{~m} \mathrm{34d}$ \\
\hline & $\begin{array}{r}\text { Prediksi } \\
\text { Opini Positif }\end{array}$ & $329=60.93 \%$ & $365=67.59 \%$ \\
\hline & $\begin{array}{r}\text { Prediksi } \\
\text { Opini Negatif }\end{array}$ & $211=39.07 \%$ & $175=32.41 \%$ \\
\hline
\end{tabular}




\section{J. Analisis Hasil Pengujian}

Pengujian pada parameter "ekonomi Indonesia" menggunakan Skenario 1, menghasilkan nilai akurasi sebesar $90.28 \%$ dengan running time 8 menit 6 detik, sedangkan pada pengujian Skenario 2 menghasilkan nilai akurasi sebesar $93.52 \%$ dengan running time 3 menit 5 detik.

Pengujian pada parameter "lapangan pekerjaan" menggunakan Skenario 1, menghasilkan nilai akurasi sebesar $81.46 \%$ dengan running time 7 menit 50 detik, sedangkan pada pengujian Skenario 2 menghasilkan nilai akurasi sebesar $77.56 \%$ dengan running time 3 menit 27 detik.

Pengujian pada parameter "rupiah" menggunakan Skenario 1, menghasilkan nilai akurasi sebesar $94.96 \%$ dengan running time 6 menit 9 detik, sedangkan pada pengujian Skenario 2 menghasilkan nilai akurasi sebesar 99.16\% dengan running time 1 menit 13 detik.

Pengujian pada "gabungan semua parameter" menggunakan Skenario 1, menghasilkan nilai akurasi sebesar $87.96 \%$ dengan running time 13 menit 18 detik, sedangkan pada pengujian Skenario 2 menghasilkan nilai akurasi sebesar $88.70 \%$ dengan running time 6 menit 34 detik.

Berdasarkan hasil pengujian yang telah dipaparkan pada Tabel 5 dan pada penjelasan diatas, dapat diketahui berdasarkan "gabungan semua parameter", performa mesin menjadi lebih baik ketika menggunakan pengujian Skenario 2 (training data B), dapat dilihat berdasarkan nilai akurasi. Hal tersebut diduga karena training data $\mathrm{A}$ yang berasal dari data tweets, menghasilkan data yang kurang bervariasi, sehingga akurasinya sedikit lebih rendah dibanding ketika mesin menggunakan training data B yang walaupun memiliki jumlah data yang terbatas, namun memiliki data yang lebih bervariasi sehingga dapat memprediksi testing data dengan lebih baik.

Berdasarkan running time pada masing-masing Skenario pengujian, baik pada pengujian untuk masingmasing parameter maupun pengujian untuk gabungan semua parameter, running time pada pengujian Skenario 1 jauh lebih panjang dibandingkan running time pada pengujian Skenario 2. Hal tersebut dikarenakan dokumen pada training data A yang digunakan pada pengujian Skenario 1 jauh lebih banyak dibandingkan dokumen pada training data $\mathrm{B}$ yang digunakan pada pengujian Skenario 2.

Berdasarkan kedua skenario pengujian yang dilakukan, jika nilai prediksi (POP dan PON) dibandingkan dengan data aktual (opini positif = 336 dan opini negatif $=204$ ), maka Skenario 1 menghasilkan prediksi dengan selisih sebanyak 7 opini. Sedangkan Skenario 2 menghasilkan prediksi dengan selisih sebanyak 29 opini. Berdasarkan perbandingan selisih yang diperoleh dengan Skenario 1 dan Skenario 2, Skenario 1 yang menghasilkan selisih lebih kecil justru memiliki nilai akurasi yang lebih rendah. Sedangkan Skenario 2 yang menghasilkan selisih lebih besar justru memiliki nilai akurasi yang lebih tinggi. Seperti pengujian pada "ekonomi Indonesia", hal tersebut dikarenakan hasil prediksi pada Skenario 1 jumlahnya lebih mendekati data aktual, namun nilai TP (True Positif) dan TN (True Negative) yang dihasilkan dari prediksi tersebut lebih rendah dibandingkan nilai TP dan TN yang dihasilkan pada Skenario 2. Maka, nilai TP dan TN yang lebih tinggi pada Skenario 2 otomatis membuat nilai akurasinya menjadi lebih tinggi dibandingkan dengan Skenario 1, walaupun memiliki selisih yang lebih besar terhadap data aktual.

Berdasarkan pada kedua Skenario pengujian (Skenario 1 dan Skenario 2), nilai akurasi tertinggi dan terendah diperoleh pada parameter yang sama, yakni terendah pada "lapangan pekerjaan" (nilai akurasi 81.46\%; 77.56\%) dan tertinggi pada "rupiah" (nilai akurasi 94.96\%; 99.16\%). Akurasi pada "lapangan pekerjaan" lebih rendah dibanding parameter lainnya dikarenakan struktur kata/kalimat pada dokumen testing data "lapangan pekerjaan" lebih kompleks dibanding parameter lainnya sehingga mesin bekerja lebih "ekstra". Sedangkan akurasi tertinggi yang diperoleh pada "rupiah" dikarenakan sebaliknya, yakni struktur kata/kalimat pada dokumen testing data "rupiah" yang lebih sederhana, sehingga mesin mampu mengklasifikasikan testing data dengan sangat baik.

Berdasarkan analisis hasil pengujian, penelitian ini mencoba mengadopsi tingkat nilai diagnosa pada Kurva ROC menurut [19] yang menyatakan:

a. Akurasi bernilai 0.90-1.00 = excellent classification

b. Akurasi bernilai $0.80-0.90=$ good classification

c. Akurasi bernilai $0.70-0.80=$ fair classification

d. Akurasi bernilai $0.60-0.70=$ poor classification

e. Akurasi bernilai 0.50-0.60 = failure

Berdasarkan tingkat nilai diagnosa di atas, klasifikasi yang dilakukan oleh opinion mining machine dapat dinyatakan sebagai "Good Classification" karena pada pengujian yang dilakukan terhadap "Gabungan Semua Parameter" (keseluruhan testing data) menghasilkan akurasi sebesar $87.96 \%$ (Skenario 1) dan akurasi sebesar $88.70 \%$ (Skenario 2).

\section{KESIMPULAN}

Penelitian yang dilakukan mampu menghasilkan opinion mining machine dengan pengimplementasian Naive Bayes Classifier sebagai algoritma pengklasifikasian, sehingga dapat mengklasifikasikan tweets masyarakat terkait kinerja presiden dalam aspek ekonomi ke dalam kelas positif dan negatif.

Berdasarkan analisis hasil pengujian, secara keseluruhan (gabungan semua parameter) menghasilkan prediksi yang didominasi oleh opini positif terhadap kinerja presiden. Namun jika dianalisis pada masingmasing parameter, "ekonomi Indonesia" dan "rupiah" menghasilkan prediksi yang didominasi dengan opini positif, sedangkan "lapangan pekerjaan" didominasi dengan opini negatif. Maka dari itu, dapat diketahui kinerja presiden pada parameter "ekonomi Indonesia" dan "rupiah" dinilai masyarakat sudah baik, dan sudah selayaknya untuk dapat dipertahankan, bahkan ditingkatkan. Sedangkan kinerja presiden terkait "lapangan pekerjaan", diketahui mayoritas masyarakat beropini negatif. Maka dari itu, diharapkan hasil tersebut dapat memotivasi presiden untuk terus meningkatkan 
performanya. Kinerja presiden terkait "lapangan pekerjaan" dapat dilakukan evaluasi kembali dengan segala upaya untuk mencari jalan keluar atas permasalahan tersebut. Pemerintah dapat rutin melakukan opinion mining (analisis sentimen) untuk mengetahui opini rakyat mengenai kinerja-kinerjanya, yang tentunya dapat menjadi salah satu pertimbangan dalam mengambil sebuah keputusan.

Mesin klasifikasi yang dihasilkan secara keseluruhan (gabungan semua parameter) dapat dinyatakan sebagai "Good Classification" dengan rentang nilai akurasi 80\%$90 \%$.

Klasifikasi menggunakan training data A yang berjumlah 600 dokumen (pengujian Skenario 1), mesin mampu mengklasifikasikan testing data (gabungan semua parameter) dengan akurasi sebesar $87.96 \%$ (running time 13 menit 18 detik). Sedangkan klasifikasi menggunakan training data $\mathrm{B}$ yang berjumlah 158 dokumen (pengujian Skenario 2), mesin mampu mengklasifikasikan testing data dengan akurasi sebesar 88,70\% (running time 6 menit 34 detik). Dapat disimpulkan, performa mesin lebih unggul ketika menggunakan training data $\mathrm{B}$ dengan akurasi yang lebih tinggi, dan running time yang jauh lebih cepat dibandingkan dengan training data A.

Pola "parameter + kata independen" yang digunakan peneliti dalam penyusunan training data B dinyatakan berhasil dan cocok untuk penelitian ini karena mesin tetap dapat mengklasifikasikan testing data dengan baik, bahkan cukup mampu meningkatkan performa mesin menjadi lebih baik.

Berdasarkan pada kedua Skenario pengujian (Skenario 1 dan Skenario 2), nilai akurasi tertinggi dan terendah diperoleh pada parameter yang sama, yakni terendah pada "lapangan pekerjaan" (nilai akurasi 81.46\%; 77.56\%) dan tertinggi pada "rupiah" (nilai akurasi 94.96\%; 99.16\%). Hal tersebut dapat dipengaruhi pada kompleksitas struktur kata/kalimat pada masing-masing testing data yang diperoleh dari tweets.

\section{DAFTAR PUSTAKA}

[1] Kumparan, "Kumparan," PT Dynamo Media Network, 20 Mei 2018. [Online]. Available: https://kumparan.com/kumparannews/indo-barometerperekonomian-jadi-masalah-utama-setelah-reformasi. [Accessed 30 Agustus 2019].

[2] N. Schoonderwoerd, "PeerReach," PeerReach, November 2013 [Online]. Available: http://blog.peerreach.com/2013/11/4-wayshow-twitter-can-keep-growing/. [Accessed 26 Juni 2019].

[3] P. Aliandu, "Twitter Used by Indonesian President: An Sentiment Analysis," Information Systems International Conference (ISICO), pp. 713-717, 2013

[4] G. A. Buntoro, "Analisis Sentimen Calon Gubernur DKI Jakarta 2017 di Twitter," INTEGER: Journal of Information Technology, vol. 2, no. 1, pp. 32-41, 2017

[5] S. Budi, "Text Mining untuk Analisis Sentimen Review Film Menggunakan Algoritma K-Means," Techno.COM, vol. 16, no. 1, pp. 1-8, 2017.

[6] I. Adiwijaya, "Text Mining dan Knowledge Discovery," Kolokium Bersama Komunitas Data Mining Indonesia \& Soft-Computing Indonesia, pp. 1-9, 2006.

[7] E. E. Pratama, "Otomatisasi Proses Penemuan Informasi Berdasarkan Kuesioner Pelaksanaan UTBK di Universitas Tanjungpura Menggunakan Metode Text Mining," in Seminar Nasional Penerapan Ilmu Pengetahuan dan Teknologi, Pontianak, 2019.
[8] N. Marres, Goldsmiths and E. Weltevrede, "Scraping the Social? Issues in Real-Time Social Research," Journal of Cultural Economy, pp. 313-335, 2013.

[9] M. A. Fauzi, "Docplayer," 2017. [Online]. Available: https://docplayer.info/43185367-Text-pre-processing-m-alifauzi.html. [Accessed 26 Agustus 2019]

[10] S. B. Kotsiantis, D. Kanellopoulos and P. E. Pintelas, "Data Preprocessing for Supervised Learning," International Journal of Computer Science, vol. 1, no. 2, pp. 111-117, 2006.

[11] L. Valatehan, M. Fachrurrozi and d. O. Arsalan, "Identifikasi Kalimat Pemborosan Menggunakan Rule Based," Annual Research Seminar, vol. 2, no. 1, 2016.

[12] K. Dave, S. Lawrence and D. M. Pennock, "Minning the Peanut Gallery: Opinion Extraction and Semantic Classification of Product Reviews," Proceedings of International World Wide Web Conference, pp. 519-528, 2003.

[13] B. Liu, Sentiment Analysis : Mining Opinions, Sentiments, and Emotions, chicago: Cambridge University Press, 2015.

[14] A. Riyanto, "Text Summarization dengan Metode K-Means Pada Artikel Berita Berbahasa Indonesia," Digital Library UNIKOM, Bandung, 2016.

[15] S. N. J. Fitriyyah, N. Safriadi, and E. E. Pratama, "Analisis Sentimen Calon Presiden Indonesia 2019 dari Media Sosial Twitter Menggunakan Metode Naive Bayes," JEPIN (Jurnal Edukasi dan Penelitian Informatika), vol. 5, no. 3, pp. 279-285, 2019.

[16] R. Feldman and J. Sanger, The Text Mining Handbook:Advanced Approaches to Analyzing Unstructured Data, Cambridge, England: Cambridge University Press, 2007.

[17] C. D. Manning, P. Raghavan and H. Schütze, Introduction to Information Retrieval, Cambridge: Cambridge University Press, 2008.

[18] G. Berliana, Shaufiah, S. Sa'adah, "Klasifikasi Posting Tweet mengenai Kebijakan Pemerintah Menggunakan Naive Bayesian Classification," E-Proceeding of Engineering, vol. 5, no. 1, pp. $1562-1569,2018$

[19] F. Gorunescu, Data Mining Concept Model Technique, Berlin: Springer-Verlag Berlin Heidelberg, 2011.

[20] J. Han, M. Kamber and J. Pei, Data Mining: Concepts and Techniques: Concepts and Techniques Third Edition, Waltham: Elsevier, 2012.

[21] D. Kuhlman, A Python Book : Beginning Python, Advanced Python, and, United States: Platypus Global Media, 2013.

[22] A. Hanafi, "Media Sosial Sebagai Penunjang Proses Perkuliahan," Jurnal Teknomatika, vol. 4, no. 1, pp. 31-44, 2011.

[23] J. L. Gibson, J. M. Ivancevich and J. H. Donnelly, Organisasi: Perilaku, Struktur, Proses. Edisi keempat, Jakarta: Erlangga, 1994.

[24] B. Prishardoyo, A. Trimarwanto and Shodiqin, Pelajaran Ekonomi SMP Kelas 2, Jakarta: PT Grasindo, 2005.

[25] B. Gunawan, H. S. Pratiwi, E. E. Pratama, "Sistem Analisis Sentimen pada Ulasan Produk Menggunakan Metode Naive Bayes," Jurnal Edukasi dan Penelitian Informatika, vol. 4, no. 2, pp. 113-118, 2018. 